\title{
THE MARKET FOR TECHNOLOGY IN THE CHEMICAL INDUSTRY : CAUSES AND CONSEQUENCES
}

Mots-clés : Industrie chimique, licences de technologie, marché de technologie.

Key words : Chemical Industry, Licensing, Market for Technology.

\section{1. - INTRODUCTION}

A firm wishing to protect its intellectual property from imitation has different options, notably patents, first mover advantage, lead time and secrecy. Although patents are often thought to be less effective at enabling the inventor to benefit from the innovation than other alternatives (Levin et al., 1987; Cohen et al., 1996), they have an important socially valuable feature that the alternatives lack. Specifically, patents can be used to sell technology, typically through licensing contracts.

This is our point of departure beyond the traditional approach to patents that has mainly focused on patents as means to exclude others. Simply put, patents can play a key role in facilitating the purchase and sale of technology, or in other words, the development and functioning of a market for technology. A market for technology helps diffuse existing technology more efficiently; it also enables firms to specialize in the generation of new technology. In turn, such specialization is likely to hasten the pace of technological change itself. The reason for focusing on the development and functioning of a market for

(*) Financial support from the The European Commission throught the TSER program, contact SOE1-CT97-1059, is gratefully acknowledged. We are indebted to Alfonso Gambardella for ongoing suggestions and discussions. We thank Eric Brousseau, an anonymous referee of this journal and participants in seminars at Stanford University, University of Stuttgart and University Carlos III (Madrid) for helpful comments on a previous draft. Ralph Landau and Martin Howard have shared their extensive knowledge of licensing practices in the chemical industry, for which we are very grateful. All errors, of course, remain our own. 
technology is that it greatly reduces the transaction costs involved in buying and selling technology, implying that innovators have the option of appropriating the rents from their innovation by means of simple contracts, instead of having to exploit the technology in-house.

However, the development of a market for technology is not an automatic outcome. It depends not only on the efficacy of technology licensing contracts (and on the strength of patents that underpin these contracts), but also on the industry structure itself. This is an important issue - Whether firms contract for technology depends not only on the transaction costs, as commonly understood, but also on historical factors. Thus, in chemicals, the presence of specialized engineering firms that licensed technology, and in other cases, provided complementary know-how for technologies developed by chemical firms played a key role. The increasing competition has also fostered the willingness of even the largest chemical firms to license their technology, while globalization and entry since world war II has meant that there exists a substantial number of chemical producers that are potential buyers of technology.

The chemical industry provides a natural framework within which to explore these themes. It is a technology-based industry with a long history of patenting and licensing. Further, as we show, transactions in technology have become widespread, with substantial variations across products.

The next section reviews the contribution of the economics literature on the role of patents in fostering innovation and facilitating the diffusion of technology. In section 3 we show how, in the past, chemical firms have used patents as one of the ways of excluding competitors and creating monopolies. However, after world war II firms started to use licensing contracts (underpinned by patents) as means to profit from innovation, leading to the development of a market for chemical process technology. As section 4 argues, patents have also facilitated the entry of specialized engineering firms and a progressive division of labor. Furthermore, as discussed in section 5, this has profoundly influenced how even large chemical producers appropriate rents from their innovations. Section 6 discusses the specific features of the chemical industry that have favored the creation of a market for technology. Section 7 summarizes and concludes the paper.

\section{2. - PATENTS, INNOVATION, AND DIFFUSION}

Much of the early economics literature on patents focused upon the trade-off between the social inefficiency due to monopoly and the social benefits from the innovation. Implicitly, a one-to-one relationship was assumed between a patent and an innovation. Although analytically convenient, this assumption obscured the point that in technologies that are cumulative or systemic, an innovation may require many different pieces of knowledge, some of which may be patented and owned by agents with conflicting interests. 
With cumulative and systemic technologies, an agent holding a patent on an important component may cause severe « holdup » problems, retarding the development of the technology (e.g. Scotchmer, 1991 ; Green and Scotchmer, 1995). In a similar vein, Merges and Nelson $(1990,1993)$ argue that broad patents increase the likelihood that an innovator would try to control future innovations based upon its own innovation, thereby slowing down the pace of technological progress.

However, the essential problem is not caused by patents, but by factors (such as negotiation costs) that prevent agents from entering into contracts for the use of patents. Thus the issue at stake is the impact that better defined patent rights would have on transaction costs. In a more recent paper, Merges (1998) uses the incomplete contracting approach (Grossman and Hart, 1986; Hart and Moore, 1990) to argue that well defined patents reduce transaction costs, and thereby help increase transactions in technology. As the examples of technology sharing agreements in the chemical industry, discussed below, show, patents play an important role in structuring complex contracts involving the exchange of technology between large firms (1).

Efficient contracting for technology is particularly important because innovations may systematically originate in firms that will not develop and utilize the knowledge themselves. Instead, a division of labor in innovative activity can exist, whereby innovations are transferred to other firms that develop and commercialize them further (Arora and Gambardella, 1994). Patents can play an important role in determining the efficiency of knowledge flows, which are critical to any knowledge-based division of labor.

This neglect of the possibility of sale of technology is rooted partly in the well-known fact that licensing contracts in the past have tended to be imperfect. As a result, innovators have been unable to appropriate a substantial share of the rents from the innovation (e.g. Arrow, 1962 ; Caves et al., 1983).

The tacitness, or more precisely, the inarticulable aspect of technology, is undoubtedly an important part of the reason why licensing is sometimes not an efficient way to appropriate rents from innovation. Many standard economic models of innovation have implicitly assumed that all useful technological knowledge, once produced is costlessly transmittable. In the vast majority of cases, this is simply untrue. In practice, much of the useful knowledge is not codified in the form of patents and blueprints (2). Often, the innovator has

(1) This is not specific to the chemical industry. Grindley and Teece (1997) report that. in cross-licensing agreements in electronics and semiconductors, the quality and the market coverage of the patent portfolios of each party is used in the calculation of balancing royalty payments. See also Hall and Ham (1999).

(2) Over two thirds of the British firms interviewed by Taylor and Silberston (197.3) said that know-how transfer was the main, or one of the main motives, behind their patent licensing agreements. 
some discretion in how she codifies, stores, and organizes this information. Strong patent protection provides incentives to codify new knowledge in ways that are meaningful and useful to others.

Moreover, to the extent that the tacitness of technology raises problems for the efficiency of contracts for knowledge, patent protection also directly affects the efficiency of the contracting process itself (Arora, 1995). Specifically, tacit technology is transferred as know-how, but contracts for know-how are typically believed to be highly imperfect (Teece, 1988). Arora (1995) shows that as long as patent scope is sufficiently broad, one can write fairly simple contracts for the exchange of technologies and related know-how. These contracts involve payments over time to provide incentives for the licensor to transfer know-how, while the patents the licensor holds prevent the licensee from behaving opportunistically. In particular, the stronger the patent protection, the lower the licensee's payoff from reneging on the contract and « inventing around » the licensor's technology. Thus Arora (1995) finds that the efficiency of technology licensing contracts in terms of transfer of know-how is greater, the stronger is the patent protection that the licensor enjoys.

In the technology licensing agreements discussed below, the vast majority are contracts that involve the transfer of know-how and unpatented technology. However, for the most part, these contracts are underpinned by patents. Industry executives we interviewed strongly believe that strong patent protection is vital for technology licensing and that absent such protection, firms would drastically reduce the extent of technology licensing.

\section{3. - THE MARKET FOR TECHNOLOGY IN CHEMICALS}

The way in which patents have been used in the chemical industry has evolved over time. Patents played an important role in the development of organic dyestuffs, the first major product area of the modern organic chemical industry, in the $1850 \mathrm{~s}$ and $60 \mathrm{~s}$. Chemical technologies, strongly based in science, were easier to codify and patent compared to mechanical technologies. The properties of synthetic dyes were dependent heavily on the structure of the molecules. Thus, understanding the structure of the dyestuff molecule and how to produce them implied that the innovator could protect the innovation through patents. German companies skillfully combined secrecy and patents to exclude competitors, both at home and abroad (see Arora, 1997, for a full discussion).

Domestic licensing was not common during this time because the dominant producers also controlled technology, not because of problems in technology licensing. Instead, the dominant producers in each market tended to form licensing and market sharing agreements with each other to keep out entrants. Indeed, the pre-WWII international chemical market has been characterized by many as a sort of a « gentlemen's club » (e.g. Spitz, 1988 ; Smith, 1992). These cartels used a number of instruments, including patent licensing agreements, to maintain market shares and deter entry. 
Some cartels were organized around a common technology, and were often initiated by the patent holder. The patent would be licensed, often in return for an equity stake, with technology flow-back agreements. For instance, the Solvay process licensees were required to share all improvements with the Solvay company, and the latter would share it with other licensees. To the extent that there were benefits to all licensees from having the Solvay process become the standard process for the production of alkali, such technology sharing cartels were mutually beneficial. In other cases, particularly during the 1920 s and 1930s, there were some prominent technology and market sharing agreements, with the agreement between Standard and IG Farben that involved technology sharing in butyl rubber, TEL and arc acetylene (from Standard), and Buna $S$ (from IG Farben) being one of the best known examples.

Though anti-competitive in intent, these arrangements did economize on scarce assets. For instance, although ICI obtained the basic patent on polyester, Du Pont had developed significant expertise in the production process based on its experience in nylon, and controlled the melt-spinning process that was crucial for successful commercialization. ICI and Du Pont had a long standing agreement that involved technology licensing as well as the extensive sharing of information and know-how. As a result, the two companies quickly settled on a suitable cross-licensing agreement.

However, it is only after world war II that firms start to use licensing as a means to profit from innovation and a market for chemical technology begins to arise. Indeed, starting from the 1950 s an increasing number of chemical processes became available for license. Landau (1966:4) writing two decades after the end of the war, noted that «... the partial breakdown of secrecy barriers in the chemical industry is increasing ... the trend toward more licensing of processes...». Importantly, these were not exclusive licenses. As Spitz (1988: 318) put it «... some brand new technologies, developed by operating (chemical) companies, were made available for license to any and all comers. A good example is the Hercules-Distillers phenol/acetone process, which was commercialized in 1953 and forever changed the way that phenol would be produced...».

Our data analysis confirms the presence of a well-established market for chemical technology during the 1980s (3). Indeed, Figure 1 shows that during the period under study only a fifth of the technology used in new chemical investments worldwide was developed in-house by the investors, while the rest was licensed in from unaffiliated sources. In monetary terms, we estimate that the

(3) All figures reported in this essay refer to our calculations of Chemical Age Project File (CAPF), a comprehensive data set on worldwide investments in chemical plants during the 1980 s, compiled by Pergamon Press, London. The data set covers about 14,000 plants constructed or under construction during the period 1980-90. CAPF discloses the information about the licensor only in half of the plants. Most of the figures provided in this paper are based on the assumption that the blanks are selected randomly. 
average annual value of the transactions in this market was between $\$ 10$ and $\$ 20$ billion (4). To put this in perspective, in 1986 the total R\&D spending of the largest 30 US chemical firms was below $\$ 8$ billion (Arora and Gambardella, 1998).

FIGURE 1 : Who was licensing chemical technologies during the 1980s

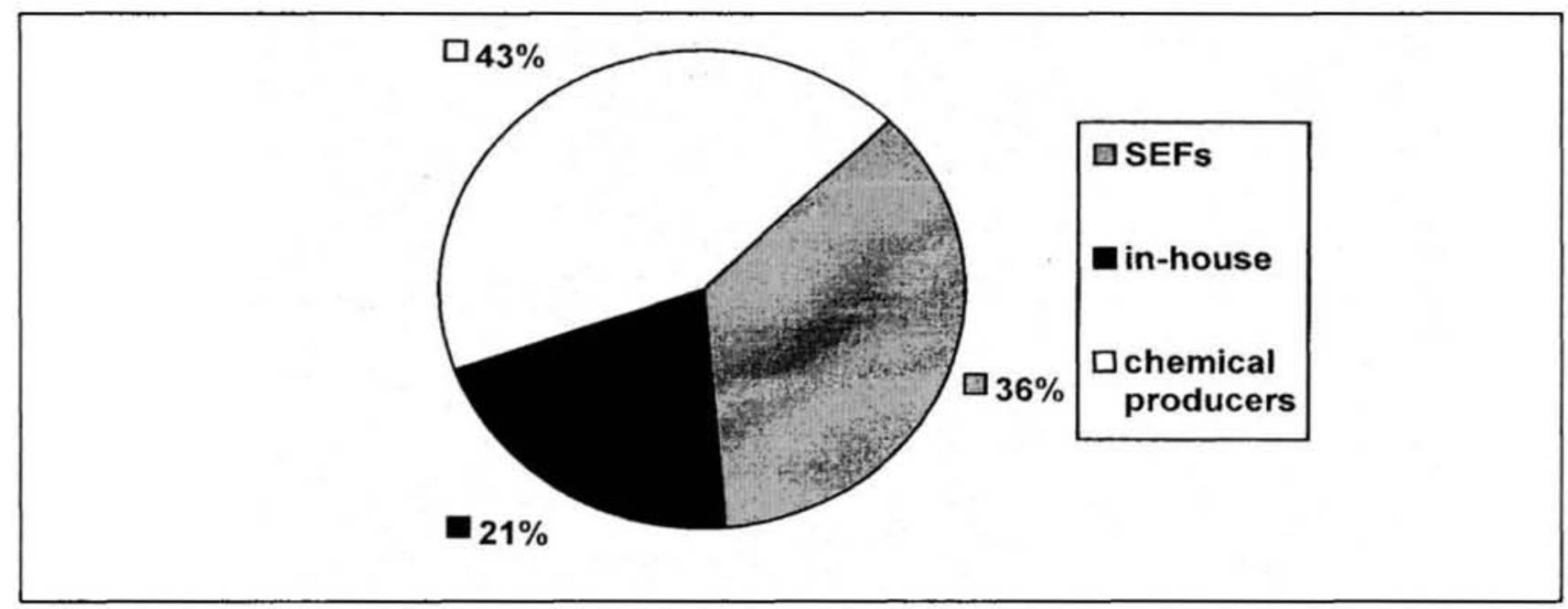

However, there are important differences across geographic areas, chemical sub-sectors and investors' sizes and nationalities in the propensity of chemical producers to rely on the market for technology. Firms investing in North America (Canada and USA) have the highest share of plants developed inhouse (more than $40 \%$ ), closely followed by firms investing in Western Europe. This share is the smallest for firms in Eastern Europe, Africa, Middle East and South America (less than $5 \%$ ). Multinational firms tend to rely more on in-house technology although this share is still sensitive to the final location of the investment. Size and nationality of the investors, which might proxy for the degree of technological capability, seem to play an important role. Large chemical corporations from advanced countries acquire less than $50 \%$ of their technology from unaffiliated sources. By contrast, third world firms rely almost completely on the market for technology (see Figure 2).

Differences across chemical sub-sectors are remarkable as well. In the aggregate, technology licensing is most common in sectors with large scale produc-

(4) The annual average number of plants constructed or under construction during the period under study is well above one thousand. Of these, half explicitly report the information about the licensor. Restricting attention to the latter, 494 plants per year were licensed in from unaffiliated sources. This figure multiplied by the average payments for a technology transaction in the chemical industry, $\$ 21.57$ million, gives the lower bound of our estimate in the text, $\$ 10$ billion. The average payments for a technology transaction in chemicals have been computed using the SDC Joint Venture database, a commercial database provided by the Securities Data Corporation, and constructed from SEF filings (10-Qs), financial journals, news wire services, proxies and quarterly reports (see Arora et al., 2000, for additional details). 
FIGURE 2 : Market for chemical technology

as a function of the investor's type

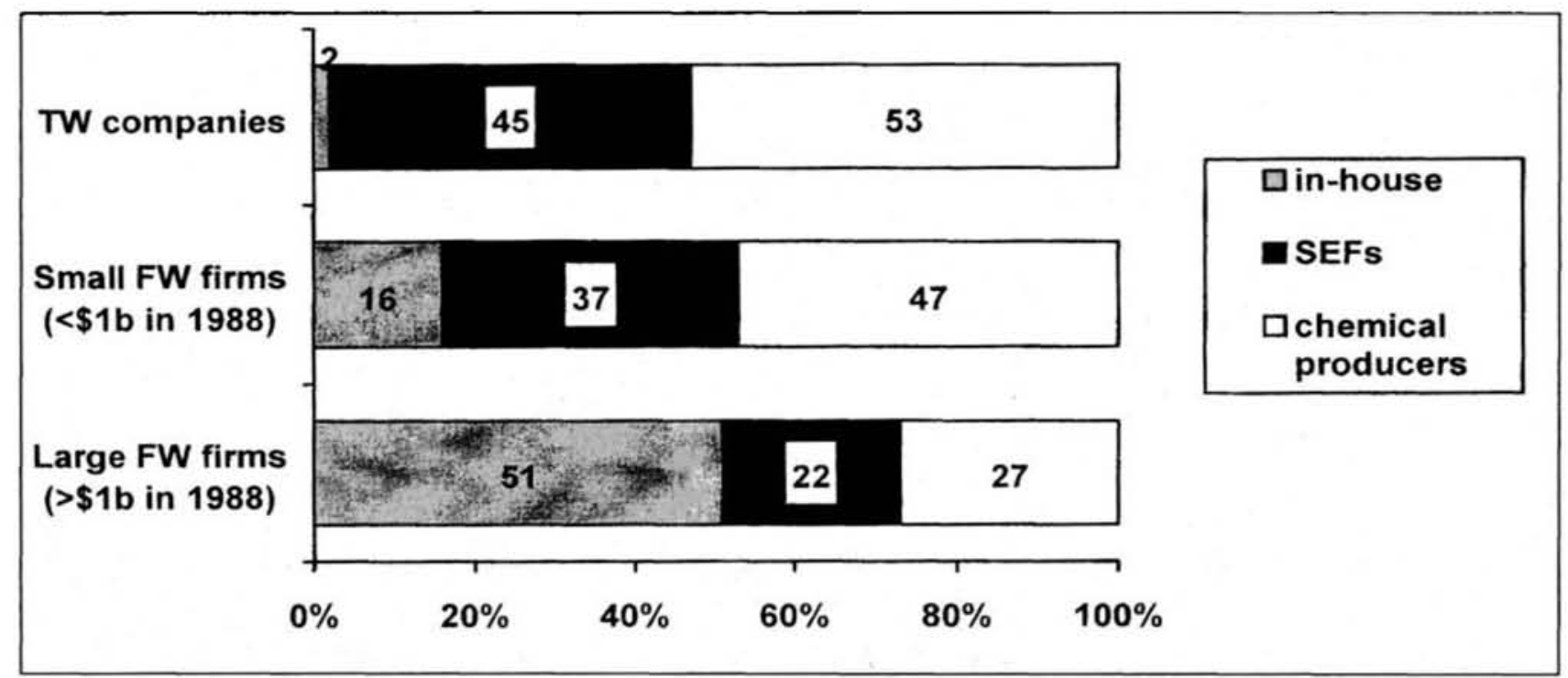

tion facilities, with relatively homogenous products, and with a large number of new plants. It is less common in sectors marked by product differentiation, custom tailoring of products for customers, and small scales of production. Indeed, in Pulp \& Paper, Gas Handling, Fertilizers, Industrial Gases and Organic Refining more than $90 \%$ of the plants involves the sale of technology between firms that are not linked through ownership ties, whereas in Pharmaceuticals, Organic Chemicals and Plastics the share is close to $50 \%$.

Finally, the market for chemical technology is more prominent in large product markets. As shown in Figure 3, the extent of the market for chemical technology moves from close to $90 \%$ in 'large' product markets (those accounting for more than 30 plants worldwide during the period under study) to $50 \%$ in 'niche' product markets (1-2 plants).

FIGURE 3 : Share of SEFs licensing by size of product markets

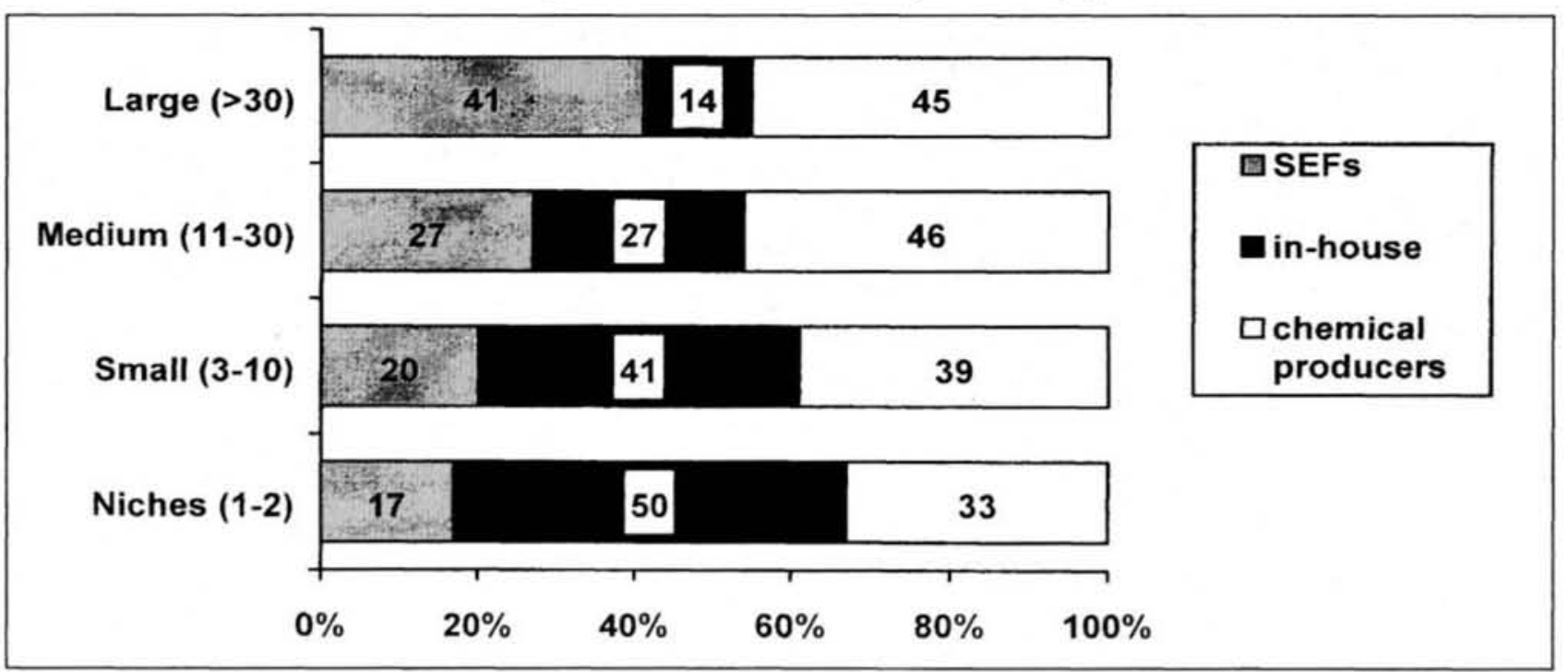


Contracts typically involve a lump sum payment that is paid in installments, starting when the contract is signed to when the plant is commissioned. In addition, there may be royalties on output for a specified period of time (royalties are more or less set by industry norms, typically between $2 \%$ and $5 \%$ ). These carry with them the right to audit, a right which is occasionally exercised. Specialized engineering firms tend to favor lump sum payments, unwilling or unable to track how the project does after commissioning.

\section{4. - SPECIALIZED ENGINEERING FIRMS AND DIVISION OF LABOR}

An important reason for the dramatic surge of licensing transactions after WWII has to do with the rise of specialized process design, engineering and construction firms (henceforth, SEFs). SEFs originated as an American phenomenon. From very early in this century, the oil firms used specialized subcontractors in various capacities : to procure or manufacture equipment such as pumps and compressors, valves, and heat exchangers, and to provide specialized sub-systems such as piping and the electrical systems. As these specialized engineering-construction firms grew in their ability to handle more sophisticated tasks, process design became a part of their activities as well. By the 1960s, SEFs dominated the design and construction of new plants and were important sources of process innovation (Freeman, 1968 ; Mansfield et al., 1977). SEFs reaped the advantages of specialization. By working for many clients, they benefited from learning by doing, and by selling repeatedly their expertise (through licenses or engineering services) they could spread the cost of accumulating that expertise over a larger output.

The importance of the SEFs lies not only in the fact that they were sources of innovations but also in how they appropriated the rents from innovation. Lacking the downstream assets required to commercialize their innovations themselves, SEFs used licensing as the principal way of profiting from their innovations. Freeman (1968) showed that for the period 1960-66, SEFs as a group accounted for about $30 \%$ of all licenses. During the 1980 s the importance of SEFs as a source of technology has increased somewhat. Figure 1 shows that in the last decade SEFs supplied the technology for more than one third of plant investments in the world as a whole, which implies that about $45 \%$ of all technologies coming from unaffiliated sources were licensed by SEFs (5).

With some prominent exceptions such as UOP and Halcon/Scientific Design, SEFs did not focus on breakthrough innovation. However, they did improve

(5) The role of SEFs varies across different sub-sectors. For instance, in Pharmaceuticals, Plastics, and Agricultural Products, SEFs account for less than $10 \%$ of all technologies from unaffiliated firms, compared to $60 \%$ in sub-sectors like Fertilizers, and Textile and Fibers. 
and modify processes developed by chemical firms and offer those for license. SEFs encouraged technology licensing in two other ways. First, as discussed below, they induced chemical firms to license their own technology. Second, they often acted as licensing agents for chemicals firms. Chemical producers often lack licensing experience and are unwilling to provide the various engineering and design services that licensees need in addition to the technology, and therefore use SEFs as licensing agents. A chemical firm will license its technology to an SEF. The latter offers a complete technology package, consisting of the core technology licensed from a chemical producer, along with know-how and installation and engineering services. This arrangement enables the licensor to benefit from the superior ability of SEFs to manage technology transfer. It also provides a buffer between the chemical firm and its licensees, limiting accidental leakage of information. From the point of view of the customer, dealing with a single source for technology, construction and engineering reduces transaction costs. The SEF can also provide better operational guarantee than if the contract were a pure technology licensing contract. (See Grindley and Nickerson, 1996, for further discussion of this topic).

Interviews with industry executives have confirmed the important role of SEFs as integrators, bundling technology licensed from a technology supplier like UCC or BP, with engineering and procurement services. It appears that whereas established firms in the U.S. or Europe are more likely to negotiate directly with the technology supplier, and then ask SEFs to bid for the engineering and construction contract, chemical firms in developing countries rely very heavily on SEFs. For them, SEFs act like one-stop-shops, procuring technology and equipment, and providing engineering and construction services.

Our data confirm this. In the 1980s, SEFs were more important sources of technology for small chemical companies and third world firms. For instance, large chemical companies from advanced countries (those with a turnover of more than \$1 billion in 1988) purchased around a fifth of their technologies from SEFs. For smaller first world companies (with less than $\$ 1$ billion of turnover in 1988) this percentage was $37 \%$, and close to $50 \%$ for third world chemical firms. See Figure 2.

Finally, Figure 3 shows that SEFs accounted for a larger share of total licensing in larger product markets. Furthermore, although not evident from the figure, larger markets also tend to have a larger fraction of the total investment from small firms and third world companies (6). In other words, the evidence is consistent with the notion that SEFs encourage investment, particularly by small firms and third world companies.

(6) The market share of big chemical companies (i.e. all firms with a turnover of more than $\$ 1$ billion in the year 1988) is $28 \%$ in "large' product markets (more than 30 plants), whereas it is about $45 \%$ in 'niche' product markets (1-2 plants). 


\section{5. — LICENSING BY CHEMICAL FIRMS}

\subsection{Empirical evidence}

The licensing activities of the SEFs have had a major effect on the rent appropriation strategies of the other players in the market as well. In a marked departure from their pre-WWII strategy of closely holding onto their technology, a number of chemical and oil companies began to use licensing as an important (although not the only) means of profiting from innovation. Licensing by chemical producers is now a significant share of all licensing in the industry. As Figure 1 shows, although SEFs play a major role as licensors, at least half of the licenses sold to unaffiliated firms are by other chemical producers themselves.

Table 1 shows the licensing strategies by a number of selected chemical corporations from advanced countries, which were especially active as technology suppliers during the $1980 \mathrm{~s}$. In particular, the last three columns of the table report the share of licenses directed to the national market, to the rest of the first world and to the third world respectively. All companies are more likely to use licensing in dealing with overseas investments, although some firms (e.g. Union Carbide, Monsanto, Exxon) also license in their home markets. On average, slightly more than one in ten licenses goes to the national market. To put this in perspective, the weight of the national market vis-à-vis the world market is also one tenth, implying that the bias towards international licensing is moderate.

TABLE 1 : Licensing strategies by some selected chemical producers

\begin{tabular}{|c|c|c|c|c|c|c|c|c|c|c|}
\hline $\begin{array}{l}\text { Company } \\
\text { Name }\end{array}$ & & $\begin{array}{l}\text { Turnov } \\
1988\end{array}$ & A & $\mathbf{B}$ & $\mathbf{C}$ & D & C/D & $\mathbf{E}$ & $\mathbf{F}$ & $\mathbf{G}$ \\
\hline Air Liquide & FRA & 3539 & 129 & 45 & 233 & 120 & 1.94 & 0.12 & 0.36 & 0.52 \\
\hline Monsanto & USA & 7453 & 113 & 31 & 204 & 590 & 0.35 & 0.26 & 0.22 & 0.52 \\
\hline Union Carbide & USA & 8324 & 106 & 37 & 192 & 59 & 3.25 & 0.22 & 0.42 & 0.36 \\
\hline Shell & UK & 11848 & 101 & 71 & 183 & 773 & 0.24 & 0.02 & 0.43 & 0.55 \\
\hline ICI & UK & 21125 & 93 & 55 & 168 & 1020 & 0.16 & 0.0 & 0.31 & 0.69 \\
\hline Air Products & USA & 2237 & 59 & 29 & 107 & 72 & 1.48 & 0.19 & 0.24 & 0.57 \\
\hline Amoco & USA & 4300 & 55 & 23 & 99,5 & NA & NA & 0.18 & 0.40 & 0.42 \\
\hline Phillips & USA & 2500 & 55 & 22 & 99,5 & NA & NA & 0.16 & 0.40 & 0.44 \\
\hline Rhone-Poulenc & FRA & 10802 & 44 & 28 & 79,6 & 632 & 0.13 & 0.0 & 0.23 & 0.77 \\
\hline Texaco & USA & 1500 & 44 & 9 & 79,6 & NA & NA & 0.18 & 0.32 & 0.50 \\
\hline BASF & GER & 21543 & 37 & 45 & 66,9 & 1010 & 0.07 & 0.03 & 0.49 & 0.48 \\
\hline Exxon & USA & 9892 & 35 & 49 & 63,3 & 551 & 0.11 & 0.23 & 0.37 & 0.40 \\
\hline Mitsui Toatsu & JAP & 2991 & 35 & 15 & 63,3 & NA & NA & 0.09 & 0.11 & 0.80 \\
\hline Hoechst & GER & 21948 & 34 & 44 & 61,5 & 1363 & 0.05 & 0.03 & 0.3 & 0.94 \\
\hline Du Pont & USA & 19608 & 33 & 66 & 59,7 & 1319 & 0.05 & 0.03 & 0.12 & 0.85 \\
\hline AVERAGE & & 9974 & 65 & 38 & 117 & 683 & 0,23 & 0.12 & 0.32 & 0,56 \\
\hline
\end{tabular}

Note: $A=$ total number of licenses in $1980-90, B=$ total number of self licenses in 1980-90, $\mathrm{C}=$ Estimated annual average licensing revenues, $\mathrm{D}=\mathrm{R} \& \mathrm{D}$ expenditures in $1988, \mathrm{E}=$ share of licenses at home, $\mathrm{F}=$ share of licenses in the rest of the first world, $G=$ share of licenses in the third world. All figures (except shares) in millions of US dollars. 
Not only do firms license extensively, many of them now explicitly consider licensing revenues as a part of the overall return from investing in technology. For instance, Union Carbide is reported to have earned $\$ 300$ million from its polyolefin licensing in 1992 (Grindley and Nickerson, 1996). More recently, both Du Pont and Dow, two chemical firms with a long tradition of exploiting technology in-house have indicated that they intend to license technology very actively. In 1994 Du Pont created a division with the specific task of overseeing all technology transfer activities. Reversing its tradition of treating in-house technology as the jewel of the crown, Du Pont has started to exploit it through an aggressive outlicensing program. Starting from 1999, this is expected to be a $\$ 100$ million per year business. On its own web page, DuPont advertises the technologies available for licensing in several areas : fibers-related, composites, chemical science and catalysis, analytical, environmental, electronics, biological. The words of Jack Krol, DuPont's president and CEO, at the 1997 Corporate Technology Transfer Meeting, emphasize this new trend :

«...For a long time, the belief about intellectual property at DuPont was that patents were for defensive purposes only. Patents and related know-how should not be sold, and licensing was a drain on internal resources ... Our businesses are gradually becoming more comfortable with the idea that all intellectual property ... is licensable for the right price in the right situation...».

Dow has also long had a reputation for «...never licensing breakthrough technology, and there was an emotional bias against licensing...» (Ed Gambrell, V.P., Dow). In 1995, it formed a licensing group with the purpose to « create more value " from its technology. Before the group was formed, Dow had licensing revenues of roughly $\$ 10-20$ million per year. It now expects to earn a $\$ 100 \mathrm{million} /$ year business by 2000 .

Finally, we have estimated the average annual licensing revenues (during the period 1980-90) for a sample of large chemical producers. These revenues amount to $\$ 26$ million, or about $10 \%$ of the mean R\&D expenditure in 1988 (for our sample). Some firms are performing well above this average. For instance, Union Carbide has licensing revenues as large as its total R\&D expenditure. Other firms like Monsanto, Shell and ICI cover respectively about $36 \%$, $24 \%, 17 \%$ of their R\&D expenditures through licensing revenues. In Table 1 we report for a selected number of firms the annual average licensing revenues (column C) and their total R\&D expenditures in 1988 (column D).

\subsection{Why is there so much licensing by chemical producers?}

This behavior of the chemical firms runs contrary to the orthodox management prescriptions (e.g. Teece, 1988). Traditional wisdom holds that licensing is undesirable because the innovator has to share the rents with the licensee, and because licensing implies increased competition and rent dissipation.

There are two, related, reasons for the change in strategy : increased competition, and technology licensing by SEFs. The presence of competing techno- 
logies drastically changes the payoff to the strategy of trying to keep one's technology in-house. For instance, suppose there are two viable processes for the production of a particular product, each owned by a different firm. If one of the firms is going to license out (sell) its technology, the best response of the other innovator may well be to license out (sell) as well.

A recent search of the trade publications turned up further evidence that shows that at least in some markets, chemical and oil companies are aggressively competing to sell technology, often in collaboration with an SEF which undertakes the provision of the engineering and other know-how. Sometimes, competitors in the market for licenses are other chemical producers. In other cases, the major competition is provided by SEFs.

In Arora and Fosfuri (1999) we develop a model of oligopolistic competition with potentially more than one technology supplier. We consider the case where at least one of the competing innovations is patented by an SEF. Lacking production facilities, an SEF has little option but to license its technology to others (7). Therefore, when one of the innovators is an SEF, the other innovator's dominant strategy is to license its innovation as well. Put it differently, in product markets where SEFs are widespread, chemical producers have no other strategic choice, but aggressively licensing themselves. Figure 4 shows that in all chemical sub-sectors in which SEFs had more than $42 \%$ of market share during the $1980 \mathrm{~s}$, the average number of licenses sold out by chemical producers was 2.8, whereas in the sub-sectors in which SEFs had less than $18 \%$ of the market, it was as little as $1.3(8)$.

Even without SEFs, a technology holder may license if the net licensing revenues are greater than the loss in profits due to increased competition in the product market. However, whereas the licensing revenues go only to the licensor, all incumbent producers potentially lose from the increased competition. In other words, licensing imposes a negative pecuniary externality upon other incumbents, which is not taken into account by the licensor. As a result, licensing can be privately profitable even if it reduces the joint profits of all incumbents.

This is exemplified by the different ways in which BP Chemicals has approached acetic acid and polyethylene. In acetic acid, BP Chemicals has strong proprietary technology, but it licenses very selectively, typically only licensing to get access to markets it would otherwise be unable to enter. By contrast, in polyethylene, BP has less than $2 \%$ of the market share. Although it has good proprietary technology as well, there are a dozen other sources of technology

(7) Our data confirm that the average number of licenses sold out by SEFs is larger than the average number of licenses sold out by producers in basically all chemical sub-sectors.

(8) Figure 4 classifies all chemical sub-sectors (23) reported in CAPF in three broad categories characterized respectively by small, medium and important presence of SEFs. It reports the average number of licenses per chemical producer. 
FIGURE 4 : Market share of SEFs and licensing by chemical producers

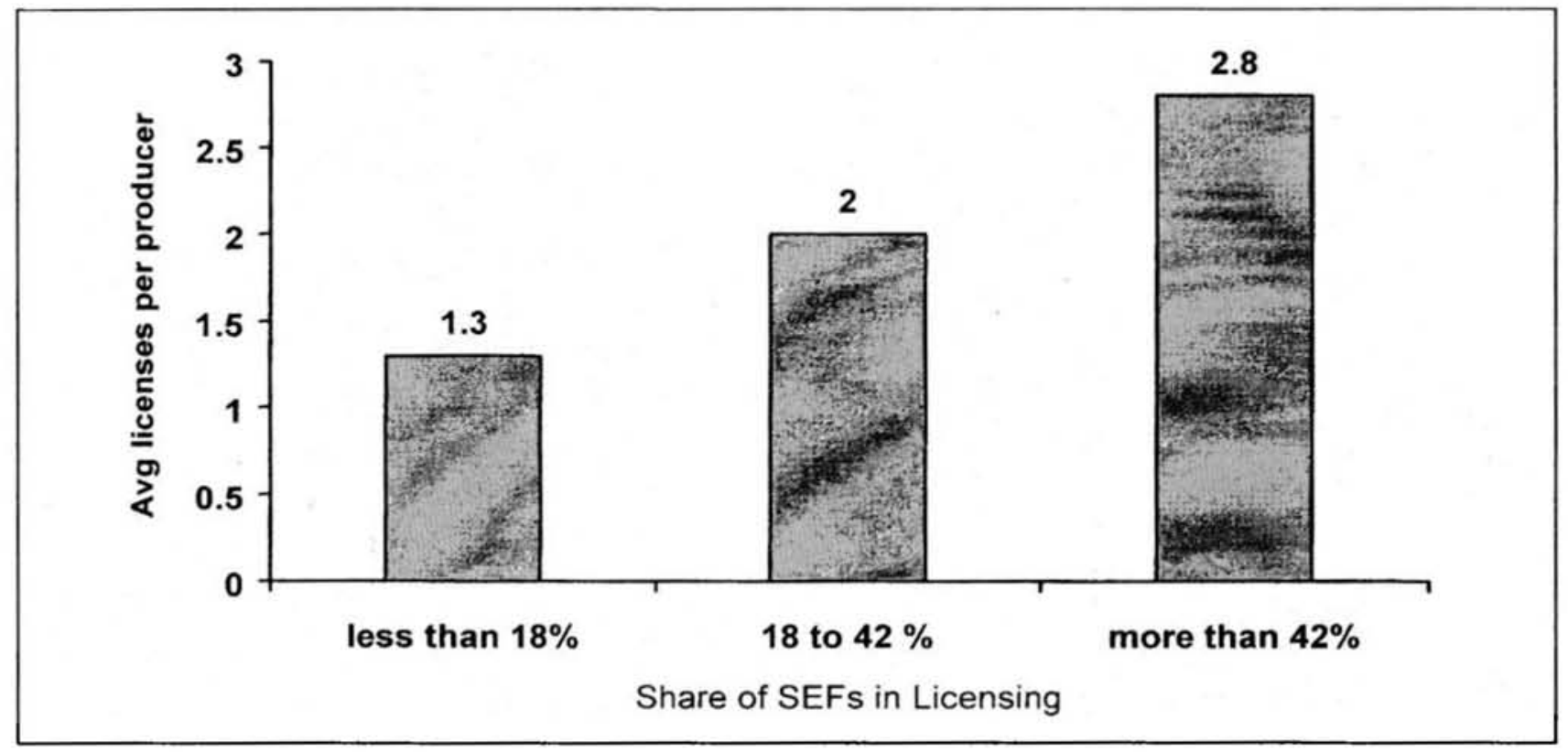

FIGURE 5 : Product differentiation and licensing

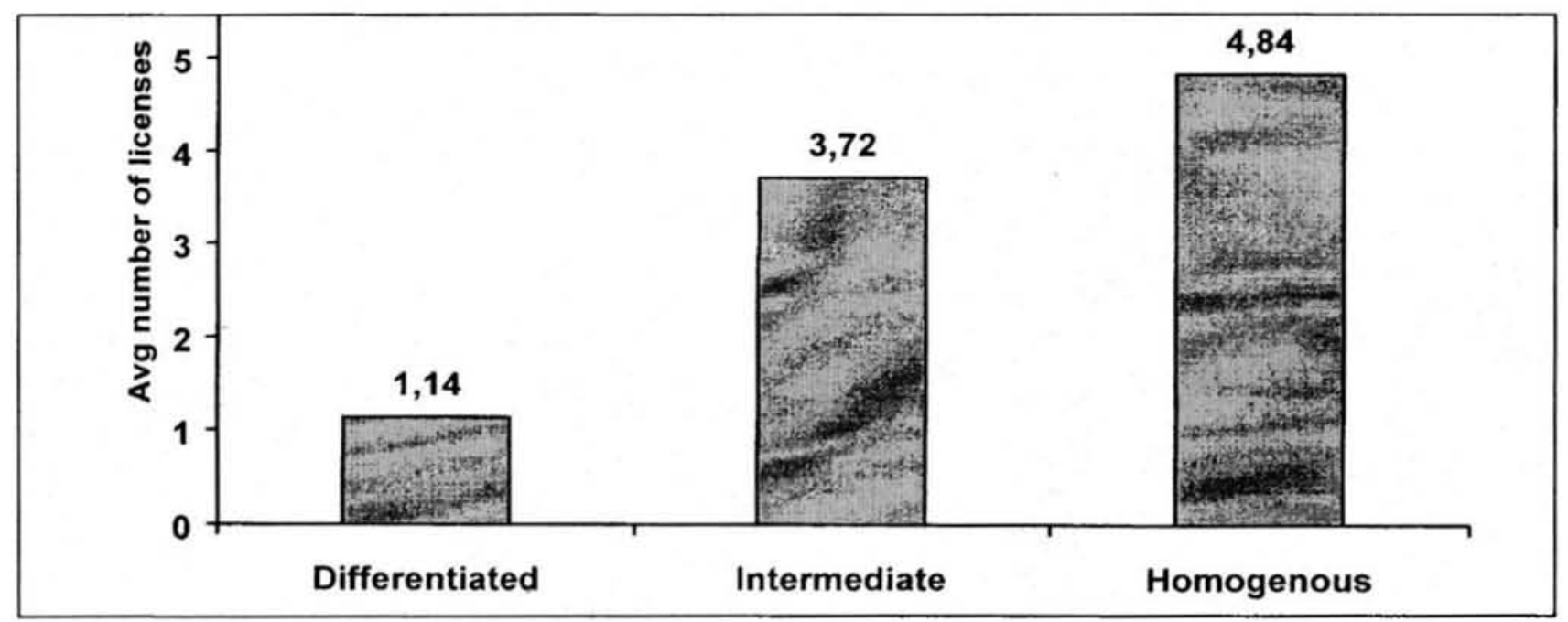

for making polyethylene. Thus, BP has licensed its polyethylene technology very aggressively, competing with Union Carbide which was the market leader in licensing polyethylene technology. Even here, BP initially tried not to license in Western Europe, where BP had a substantial share of polyethylene capacity. However, other licensors continued to supply technology to firms that wished to produce polyethylene in Western Europe, with the result that BP found that it was losing potential licensing revenue without any benefits in the form of restraining entry.

In Arora and Fosfuri (1999), we formally show that the more homogeneous the product, the greater the negative externality to other incumbents, and the greater the incentives to license. We find that technology licensing is most common in sectors with large scale production facilities, with relatively homogenous products, and with a large number of new plants. It is less common in 
sectors marked by product differentiation, custom tailoring of products for customers, and small scales of production. Figure 5 confirms this finding. It classifies all chemical sub-sectors reported in CAPF in three broad categories of product differentiation : homogenous, intermediate and differentiated. The figure shows that the average number of licenses per patent-holder increases as the product market becomes more homogenous (9).

Finally, most of the licensing takes place for processes. New products are far less likely to be licensed, at least in the initial stage of their life cycles. In this case, the profit loss due to competition would be felt almost entirely by the licensor since by definition there would not be any other incumbent producers of the product. These incentives are reinforced by the unimportance of SEFs in product innovation.

\section{6. - WHY IN CHEMICALS?}

Licensing and the presence of a market for technology are not limited to the chemical industry. In Arora, Fosfuri and Gambardella (2000) we provide evidence of extensive licensing in sectors like semiconductors, electronics, industrial machinery, equipment and business services, biotechnology, and several examples of licensing strategies by large established producers like IBM, Texas Instruments, Boeing, Philips, Procter \& Gamble, General Electric. Nevertheless, it is true that the use of licensing as a strategy of rent appropriation is less developed outside of chemicals, particularly for processes (see also Anand and Khanna, 1997).

As discussed earlier, technology licensing may be hindered either because licensing contracts are very inefficient or because it is not in the strategic interest of the technology holder to license the technology. Licensing contracts can be inefficient due to the need to transfer know-how and due to information asymmetries. Both are closely related to the strength of patent protection.

In the chemical industry, unlike most others, chemical processes can be effectively protected through patents. As a result, even the valuable unpatented know-how, needed to use the technology, can be licensed. Patents pertain to that part of the discovery that is codified. Therefore the effectiveness of patents depends on how cheaply and effectively new ideas and knowledge can be articulated in terms of universal categories. When innovations cannot be described

(9) Our measure of product differentiation was computed as follows. CAPF classifies the chemical plants within each sub-sector in more disaggregated process technology classes. We use the counts at this disaggregated level to compute an equidistribution index at the subsector level. Our index of product differentiation takes the value of 0 if the products are homogenous and the value of 100 if they are totally differentiated. We have also tried alternative measures of product differentiation, such as the entropy index and the Herfindahl index, with substantially similar results 
in terms of universal and general categories, sensible patent law can only provide narrow patent protection. During the 1860 s, when synthetic dyestuffs first appeared, their structure was poorly understood, as were the reaction pathways and processes. Thus broad patents led to extensive litigation and retarded the development of technology. In France, an excessively broad patent on aniline red was construed to include all processes for making the red aniline based dye, even though it was quite clear that the structure of aniline dyes was as yet unknown. There were long and bitter disputes in England about the validity of the Medlock patent for magenta (another aniline dye) that turned on whether the appropriate definition of « dry » arsenic acid included the water of hydration (Travis, $1993: 104-137$ ).

Arora and Gambardella (1994) point out that technological knowledge that is closely related to broad engineering principles and physical and chemical « laws » is more readily codifiable. Chemical engineering developed more general and abstract ways of conceptualizing chemical processes, initially in the form of unit operations, and later in terms of concepts such as mass and energy transfer. A number of different processes could be conceived of in terms of these more elementary units. A chemical engineer could therefore see common elements across a number of processes that might appear very different and diverse to a chemist from an earlier generation. Chemical engineering (and the concomitant developments in polymer science and surface chemistry) thus provided the language for describing more precisely the innovations to be protected.

In other words, patents work well in the chemical industry because the object of discovery can be described clearly in terms of formulae, reaction pathways, operating conditions and the like (e.g. Levin et al., 1987). But it is not merely that the object of discovery is more discrete in the sense of being a particular compound. Rather, it is the ability to relate the "essential » structure of the compound to its function. This allows a patent to include within its ambit inessential variations in structure, as in minor modifications in side chains of a pesticide (10). In fact, chemical patents frequently use Markush structures to define the scope of the claim (11). The use of Markush structures permits a succinct and compact description of the claims and allows the inventor to protect the invention for sets of related compounds without the expense (and tedium) of testing and listing the entire set. The ability to explicate the underlying scientific basis of the innovation allows the scope of the patent to be delimited more clearly. The obvious extensions can be foreseen more easily and described more compactly.

(10) In some instances, seemingly minor variations in side chains can have significant biological effects. Therefore, what is a " minor » variation is itself determined by the state of the current understanding of the relation between structure and function.

(11) A Markush structure is best understood as a language for specifying chemical structures of compounds, which allows generic representation for an entire set of related compounds. See Maynard and Peters (1991: 71) for details. 


\section{7. - CONCLUSIONS}

We have argued that there exists a functioning market in chemicals where process technologies are sold through arm's length license contracts. We have documented the substantial extent of technology licensing in the chemical industry, involving both specialized engineering firms and chemical producers themselves. The existence of this market for technology has contributed to a faster worldwide diffusion of the chemical technology and to make the chemical industry a truly global industry. This process has progressed to the point where licensing is an integral part of the technology strategies of even the largest chemical firms.

Such widespread licensing would be unlikely without a well-functioning patent system : transaction costs involved in contracting for technology would be larger and contracts for know-how less efficient. Although further research is needed, we believe that patents have worked well in the chemical industry because the underlying knowledge base - chemistry and chemical engineering - has been very successful in clarifying the relationship between structure and function. A chemical invention can be described clearly in terms of structure, reaction pathways, or operating conditions, with a reasonably clear sense of the limits of the invention.

While patents are necessary for a market for technology, they are by no means sufficient. Firms that specialize in the design, engineering and construction of chemical plants emerged and some developed proprietary technologies that they offered for license, at a time when many firms, all over the world, were looking to acquire chemical technologies. SEFs induced chemical firms to license their technology as well. In addition, SEFs reduced transaction costs by acting as licensing agents for chemical firms and by bundling technology with complementary engineering, design and construction capabilities valuable to potential buyers of technology. The presence of SEFs, induced entry by a number of firms, increasing the number of potential technology buyers. The net result was a « thicker » and a more efficient market for technology. 


\section{REFERENCES}

ANAND, B.N., and KHANNA, T., 1997, «Intellectual property rights and contract structure ", working paper 97-016, Harvard Business School.

ARORA, A., 1995, "Licensing Tacit Knowledge : Intellectual Property Rights and the Market for Know-how », Economics of Innovation and New Technology 4, 41-59.

ARORA, A., 1997, « Patent, licensing and market structure in the chemical industry », Research Policy 26, 391-403.

ARORA, A., and FOSFURI, A., 1999, « Licensing the Market for Technology », CEPR Discussion Paper 2284, London, UK.

ARORA, A., FOSFURI, A., and GAMBARDELLA, A., 2000, Markets for technology (Why do we see them, why don't we see more of them and why we should care), unpublished manuscript.

ARORA, A., and GAMBARDELLA, A., 1994, « The changing technology of technological change : General and abstract knowledge and the division of innovative labour », Research Policy 23, 523-532.

ARORA, A., and GAMBARDELLA, A., 1998, " Evolution of Industry Structure in the Chemical Industry », in Arora, A., Landau, R., and Rosenberg, N. (eds.), « Chemicals and Long Term Economic Growth », John Wiley and Sons, New York.

ARROW, K.J., 1962, "Comments on case studies », in Nelson R.R. (ed.), "The Rate and the Direction of Inventive Activity : Economic and Social Factors », Princeton, NJ, Princeton University Press.

CAVES, R., CROOKEL, H., and KILLING, J.P., 1983, "The imperfect market for technology licensing ", Oxford Bulletin of Economics and Statistics, 249-267.

COHEN, W., NELSON, R., and WALSH, J., 1996, «Appropriability Conditions and Why Firms Patent and Why They Do Not in the American Manufacturing Sector », paper presented at the OECD Conference on New Indicators for the Knowledge Based Economy.

FREEMAN, C., 1968, «Chemical Process Plant : Innovation and the World Market », National Institute Economic Review 45(August), 29-51.

GREEN, J., and SCOTCHMER, S., 1995, « On the Division of Profit in Sequential Innovations ", Rand Journal of Economics 26, 20-33.

GRINDLEY, P., and NICKERSON, J., 1996, "Licensing and Business Strategy in the Chemicals Industry », in Parr, R., and Sullivan, P. (eds.), "Technology Licensing : Corporate Strategies for maximizing Value », John Wiley and Sons, New York.

GRINDLEY, P., and TEECE, D.J., 1997, "Licensing and Cross-Licensing in Semiconductors and Electronics ", California Management Review 39(2), 8-41.

GROSSMAN, S., and HART, O., 1986, «The Costs and Benefits of Ownership : A Theory of Vertical and Lateral Integration », Journal of Political Economy 94, 691-719.

HALL, B.H., and HAM, R., 1999, "The Patent Paradox Revisited : Determinants of Patenting in the US Semiconductor Industry, 1980-1994 », NBER working paper 7062, Cambridge, MA.

HART, O., and MOORE, J., 1990, « Property Rights and the Nature of the Firm », Journal of Political Economy 98, 1119-1158.

LANDAU, R., 1966, «The Chemical Plant : From Process Selection to Commercial Operation », Reinhold Publishing Co., New York.

LEVIN, R.C., KLEVORICK, A.K., NELSON, R.R., and WINTER, S.G., 1987, « Appropriating the returns from industrial R\&D ", Brookings Papers on Economic Activity 14, 551-561.

MANSFIELD, E., el al., 1977, "The Production and Application of New Industrial Technology ", Norton \& Company, New York.

MAYNARD, J.T., and PETERS, H.M., 1991, « Understanding Chemical Patents : A Guide for the Inventor », American Chemical Society, Washington, DC.

MERGES, R., 1998, " Property Rights, Transactions, And The Value of Intangible Assets ", mimeo, University of California at Berkeley, School of Law.

MERGES, R., and NELSON, R., 1990, "On the Complex Economics of Patent Scope ", Columbia Law Review 90, 839-916. 
MERGES, R., and NELSON, R., 1993, « On limiting or encouraging rivalry in technical progress : The effect of patent scope decisions ", mimeo, Columbia University.

SCOTCHMER, S., 1991, « Standing on the shoulders of giants : Cumulative research and patent law », Journal of Economic Perspectives 5(1), 29-41.

SMITH, J.K., 1992, « National goals, industry structure, and corporate strategies : Chemical cartels between the wars », in Kudo, A., and Hara, T. (eds.), « International Cartels in Business History ", University of Tokyo Press, Tokyo.

SPITZ, P.H., 1988, « Petrochemicals : The Rise of an Industry », John Wiley, New York.

TAYLOR, C.A., and SILBERSTON, Z.A., 1973, « The Economic Impact Of The Patent System : A Study Of The British Experience ", University of Cambridge, D.A.E. monograph 23, Cambridge, CUP.

TEECE, D.J., 1988, « Technological Change and the Nature of the Firm », in Dosi et al. (eds.), «Technological Change and Economic Theory », Pinter Publishers, London.

TRAVIS, A.S., 1993, «The Rainbow Makers : The Origins of the Synthetic Dyestuffs Industry in Western Europe », Associated University Presses. 